\title{
Subpopulations of Gastric Myenteric Neurons Are Differentially Activated via Distinct Serotonin Receptors: Projection, Neurochemical Coding, and Functional Implications
}

\author{
Klaus Michel, Holger Sann, Cornelia Schaaf, and Michael Schemann \\ Physiologisches Institut, Tierärztliche Hochschule, D-30173 Hannover, Germany
}

\begin{abstract}
The enteric nervous system coordinates various gut functions. Functional studies suggested that neurotransmitters and neuromodulators, one of the most prominent among them being $5-\mathrm{HT}$, may act through a specific modulation of ascending and descending enteric pathways. However, it is still mostly unknown how particular components of enteric reflex circuits are controlled. This report describes experiments aimed at identifying a differential activation of enteric pathways by 5-HT. Electrophysiological and immunohistochemical methods were combined to investigate the projection pattern and the transmitter phenotype of 5-HT-sensitive gastric myenteric neurons. Of 294 intracellularly labeled neurons, $60.5 \%$ showed responses mediated via $5-\mathrm{HT}_{3}$ receptors, $11.3 \%$ were $5-\mathrm{HT}_{1 \mathrm{P}^{-}}$ responsive, $3.7 \%$ exhibited both $5-\mathrm{HT}_{3}$ and $5-\mathrm{HT}_{1 \mathrm{P}}$ receptormediated depolarization, and $24.5 \%$ were not responding to $5-\mathrm{HT}$. The $5-\mathrm{HT}_{3}$-responsive cells were mainly cholinergic $(79 \%)$ and had ascending projections, whereas the $5-\mathrm{HT}_{1 \mathrm{P}^{-}}$ responsive cells had primarily descending projections and were
\end{abstract}

nitrergic (67\%). Substance P-positive neurons were cholinergic; most of the cells $(75 \%)$ exhibited $5-\mathrm{HT}_{3}$ mediated responses and had ascending projections. Muscle strip recordings supported the functional significance of the differential location of 5-HT receptor subtypes. Thus, contractile responses of gastric circular muscle strips were dose-dependently increased by a $5-\mathrm{HT}_{3}$ and decreased by a $5-\mathrm{HT}_{1 \mathrm{P}}$ agonist. Results indicated that excitatory ascending enteric pathways consisting of cholinergic, substance Pergic neurons were activated by $5-\mathrm{HT}_{3}$ receptors, whereas $5-\mathrm{HT}_{1 \mathrm{P}}$ receptors were involved in activation of inhibitory descending pathways using nitrergic neurons. This suggested that different effects of 5-HT on gastric functions are related to specific activation of receptors located on different subsets of enteric neurons.

Key words: enteric nervous system; serotonin; serotonin receptors; choline acetyltransferase; nitric oxide; NADPH-diaphorase; substance P; gastric motility; stomach; guinea pig
The enteric nervous system, located within the gut wall, plays a key role in the neuronal control of gastrointestinal functions (Wood, 1994; Furness et al., 1995). The control is thought to be achieved by a local network of different neuronal subpopulations, which function as motor neurons, interneurons, or sensory neurons. Combination of electrophysiological characterization of neurons, intracellular staining techniques, immunohistochemistry, and tracing studies has been used to characterize subpopulations of enteric neurons that differed in their functional properties, their neurochemical coding, and their projections. The results of such studies led to models of enteric circuits involved in the control of motor functions (Wood, 1994; Furness et al., 1995; Costa et al., 1996). The basis for these models is the peristaltic reflex, consisting of ascending excitation and descending inhibition of the muscle (Bayliss and Starling, 1899). The underlying hardwired enteric circuits might be operative throughout the gut, and the ascending and descending motor neurons involved in this polarized reflex may be characterized by their cholinergic and nitrergic phenotype (Schemann and Schaaf, 1995; Costa et al., 1996). How the activity of certain components of such a polarized reflex might be controlled and modulated is still mostly unknown.

\footnotetext{
Received March 4, 1997; revised July 31, 1997; accepted August 1, 1997.

This work was supported by Deutsche Forschungsgemeinschaft Grants Sche 267/4-2 and SFB 280.

Correspondence should be addressed to Dr. Michael Schemann, Department of Physiology, School of Veterinary Medicine, Bischofsholer Damm 15/102, D-30173 Hannover, Germany.

Copyright (C) 1997 Society for Neuroscience $\quad 0270-6474 / 97 / 178009-09 \$ 05.00 / 0$
}

Because the gut is the major source of 5-hydroxytryptamine (5-HT), one candidate for the activation and modulation of neuronal enteric circuits is 5-HT (Gershon et al., 1990). Activation of 5 -HT receptors can modulate gut motility and has prokinetic effects (Gershon et al., 1990; Read and Gwee, 1994). Although 5 -HT is found in a subpopulation of myenteric interneurons (Schemann et al., 1995; Costa et al., 1996), the major source for 5-HT is the enterochromaffin(-like) cells of the mucosa. In the intestine, 5-HT released from enterochromaffin cells has been shown to activate enteric neurons and initiate the peristaltic reflex (Kirchgessner et al., 1992, 1996; Yuan et al., 1994; Wade et al., 1996). Furthermore, 5-HT can also be released from mast cells (Wang et al., 1995). This indicates that 5-HT can be involved in physiological and pathophysiological mechanisms.

In the isolated stomach, 5-HT evoked inhibition and activation of motility (Bülbring and Gershon, 1967; Gershon, 1967). Previous studies on gastric myenteric neurons demonstrated that 5-HT excited the majority of the neurons via $5-\mathrm{HT}_{3}$ and to a much lesser extent via 5-HT 1 p receptors (Schemann, 1991). There is evidence that 5-HT can induce cholinergic contractions and nitrergic relaxation in the stomach and intestine (Meulemans et al., 1993; Fox and Morton, 1990; Buchheit and Buhl, 1994; Briejer et al., 1995). These data suggest that 5-HT stimulates enteric circuits in the stomach, but the neuronal mechanism and the different 5-HT receptor types involved are not known. Furthermore, information on the neurotransmitters used by 5-HT-responsive neurons and their projections has not been obtained.

We have therefore performed experiments to analyze the type 
of neurons responding to 5-HT. Intracellular recordings were performed on myenteric neurons of the gastric corpus to characterize their responsiveness to 5-HT. The projection of intracellularly labeled neurons and their neurochemical coding were determined. The data demonstrated that myenteric neurons with $5-\mathrm{HT}_{3}$ responses were preferentially ascending cholinergic neurons, whereas neurons with $5-\mathrm{HT}_{1 \mathrm{P}}$ responses were preferentially descending nitrergic neurons.

\section{MATERIALS AND METHODS}

Preparation. Experiments were performed on the isolated gastric corpus of the guinea pig in vitro. Guinea pigs of both sexes, weighing 200-300 $\mathrm{gm}$, were killed by cervical dislocation, and the stomach was quickly removed. A piece of the parietal gastric corpus $(20 \times 25 \mathrm{~mm})$ was dissected and was pinned out flat in a dissection dish, which was continuously superfused with ice-cold Krebs' solution. The mucosa was removed with fine forceps and scissors. A strip of the circular muscle (about $3 \mathrm{~mm}$ wide), running from the pars cardiaca to the greater curvature was carefully removed, and the underlying myenteric plexus was exposed. For recording, a $15 \times 20 \mathrm{~mm}$ piece was pinned into a $5 \mathrm{ml}$ recording chamber. The recording chamber was continuously perfused with Krebs' solution at $37^{\circ} \mathrm{C}$ at a rate of $8 \mathrm{ml} / \mathrm{min}$. The Krebs' solution contained (in mM) $117 \mathrm{NaCl}, 4.7 \mathrm{KCl}, 1.2 \mathrm{MgCl}_{2}, 1.2 \mathrm{NaH}_{2} \mathrm{PO}_{4}, 25$ $\mathrm{NaHCO}_{4}, 2.5 \mathrm{CaCl}_{2}$, and 11 glucose and was continuously gassed with $95 \% \mathrm{O}_{2} / 5 \% \mathrm{CO}_{2}$. To reduce smooth muscle contraction nifedipine was added at a final concentration of $1 \mu \mathrm{M}$.

Electrophysiology. The experiments were done under visual control using an Olympus (Tokyo, Japan) IMT 2 inverted microscope equipped with Hoffmann modulation optics. Intracellular recordings were performed with glass microelectrodes filled with $0.5 \mathrm{M} \mathrm{KCl}$ containing $1 \%$ neurobiotin. The electrodes had resistance between 150 and $200 \mathrm{M} \Omega$. Signals were amplified (Intra 767; W PI, New Haven, CT), displayed on an oscilloscope (DSO 420; Gould Instruments, Valley View, OH) and a chart recorder (Gould TA 11), and stored using a digital audio tape recorder (DTR-1202; Biological Science Instruments, Claix, France). No filters were applied to the stored data. Data were analyzed and displayed off-line using a Macintosh computer and a MacLab system (MacLab 4 s/e with Chart 3.5.1 software; AD Instruments, Castle Hill, Australia).

Impaled myenteric neurons were first classified by their response to intracellular stimulation (rectangular pulses, 0.1-0.3 nA; duration, 300 msec) according to the method of Schemann and Wood (1989). Neurons that responded with more than three action potentials corresponded to gastric I cells; neurons with only one to three action potentials corresponded to gastric II cells. Neurons in which no action potential could be evoked were termed gastric III and were only included if they received synaptic input. The neurons were then filled with neurobiotin using current pulses of $0.3 \mathrm{nA}, 0.3 \mathrm{~Hz}$, pulse width $300 \mathrm{msec}$ for $3 \mathrm{~min}$.

Serotonin (5-hydroxytryptamine creatinine sulfate complex; SigmaAldrich, Deisenhofen, Germany) was applied to the cells by pressure ejection (50-900 msec) from a spritz pipette directed toward the impaled ganglion cell. Stock solutions from 5 - $\mathrm{HT}(10 \mathrm{~mm}$ in $0.9 \% \mathrm{NaCl})$ and fast green (Sigma, St. Louis, MO) $(10 \mathrm{~mm}$ in $0.9 \% \mathrm{NaCl})$ were diluted in Krebs' solution to obtain final concentrations of $1 \mathrm{~mm}$ for serotonin and $0.5 \mathrm{~mm}$ for fast green in the spritz pipette. Fast green was used for visual control of drug ejection. Pressure ejection with fast green solution only had no effect on the neurons. To detect changes in membrane resistance or excitability induced by 5-HT, short hyperpolarizing or subthreshold depolarizing current pulses were used.

Immunohistochemistry. At the end of the electrophysiological experiments the tissue was either immediately fixed with $2 \%$ paraformaldehyde and $0.2 \%$ picric acid in $0.1 \mathrm{M}$ phosphate buffer overnight at $4^{\circ} \mathrm{C}$ or treated with colchicine in an organotypic culture before the fixation. Colchicine treatment was performed to increase the levels of substance $\mathrm{P}$ in the myenteric neurons. The tissue was washed with sterile Krebs' solution, pinned into a sterile petri dish, and incubated in culture medium (DMEM/F-12 with $10 \%$ heat-inactivated fetal calf serum, $100 \mathrm{IU} / \mathrm{ml}$ penicillin, $0.1 \mathrm{mg} / \mathrm{ml}$ streptomycin, $2.6 \mu \mathrm{g} / \mathrm{ml}$ amphotericin $\mathrm{B}$, and 50 $\mu \mathrm{g} / \mathrm{ml}$ gentamicin at $\mathrm{pH} 7.4$; all chemicals by Sigma) containing $60 \mu \mathrm{M}$ colchicine and $1 \mu \mathrm{M}$ nifedipine. The petri dish was kept in a humidified incubator at $37^{\circ} \mathrm{C}$ in an atmosphere of $5 \% \mathrm{CO}_{2}$ and air. It was placed on a rocking tray shaking at a frequency of about $0.5 \mathrm{~Hz}$. After $16 \mathrm{hr}$ the tissue was fixed for $4 \mathrm{hr}$ at room temperature.

For the immunohistochemistry, fixed tissue was washed three times in
$0.1 \mathrm{M}$ phosphate buffer for $10 \mathrm{~min}$ and preincubated for $1 \mathrm{hr}$ in $0.1 \mathrm{M}$ PBS containing $4 \%$ goat serum and $0.5 \%$ Triton X-100. After preincubation, the tissue was exposed to a mixture of primary antisera diluted in PBS containing serum and Triton X-100 for $18 \mathrm{hr}$ at room temperature. The following primary antisera were used: anti-choline acetyltransferase (ChAT) raised in rabbits (P3YEB, 1:2000) (Schemann et al., 1995) and rat monoclonal anti-substance P (SP, 1:1000; Fitzgerald, Concord, MA). Antibody specificity has been published previously (Schemann et al., 1995). Usually, double labeling for SP and ChAT was applied. After washing in PBS (three times for $10 \mathrm{~min}$ each), the preparation was incubated for $2 \mathrm{hr}$ in buffer solution containing streptavidin-Texas Red (1:1000; Life Technologies, Gaithersburg, MD) for labeling the neurobiotin-filled cells and the respective secondary antibodies. The following secondary antisera were used: goat anti-rat $\mathrm{IgG}$ conjugated to dichloro-triazinyl aminofluorescin (DTAF, 1:200; Dianova, Hamburg, Germany) and goat anti-rabbit IgG conjugated to 7-amino-4methylcoumarin-3-acetic acid (AMCA, 1:50; Dianova) for $2 \mathrm{hr}$ at room temperature. The tissues were further rinsed three times in PBS and mounted in a glycerol solution (AF1; Citifluor, Canterbury, UK). The fluorescence microscope for the examination of the preparations was an Olympus IX 70 with filter cubes UM41007 [beam splitter 565 DCLP; excitation (Ex), HQ545/30X; emission (Em), HQ610/75M] for Texas Red, U-MNIBA [beam splitter DM505; Ex, band pass (BP) 470-490; Em, D520] for DTAF, and U-MWU (beam splitter DM400, Ex, BP 330-385; Em, BP 460-490) for AMCA. There was no cross-detection between the three fluorophor-filter cube combinations.

The preparations were also analyzed using an image analysis system. Pictures were acquired with a black-and-white video camera (model 4910; Cohu Inc., San Diego, CA) connected to a Macintosh computer and controlled by IPLab Spectrum 3.0 software (Signal Analytics, Vienna, VA). Frame integration and contrast enhancement were the only functions used for picture processing. Digitized photomicrographs for each individual neuron were stored on the computer for further analysis. The axons of individual neurons were traced throughout the preparation to define the direction of the projection and to localize varicose segments or endings, as has been described previously (Schemann and Schaaf, 1995). Neurons with axonal projections toward the gastric fundus were defined as ascending neurons, whereas neurons with projections toward the gastric antrum were defined as descending neurons. Neurons with endings $<0.1 \mathrm{~mm}$ distance from the cell body were classified as local neurons.

Histochemical demonstration of NADPH-diaphorase. After complete analysis of the projection and the immunohistochemical coding, tissues were processed for the detection of NADPH-diaphorase activity. In the guinea pig stomach, NADPH-diaphorase activity labeled identical cells as having nitric oxide synthase immunoreactivity and can therefore be used as a marker for nitrergic neurons (Schemann et al., 1995). Preparations were incubated ( $30 \mathrm{~min}-2 \mathrm{hr}$ ) in $0.1 \mathrm{M}$ phosphate buffer, $\mathrm{pH} 8$, containing $0.05 \mathrm{mg} / \mathrm{ml} \beta-\mathrm{NADPH}, 0.1 \mathrm{mg} / \mathrm{ml}$ nitro blue tetrazolium, and $0.5 \%$ Triton $\mathrm{X}-100$ at $37^{\circ} \mathrm{C}$. To stop the reaction, the tissues were repeatedly rinsed in phosphate buffer. The tissues were then mounted on slides and coverslipped. Neurons were then reanalyzed using the image analysis system.

Differences between the distributions or different subpopulations were tested using the $\chi^{2}$ test with a significance level of $p<0.05$. Differences in membrane potential were tested with the Mann-Whitney rank sum test $(p<0.05)$.

Organ bath experiments. To record contractions of the circular muscle, mucosa-free strips of the parietal gastric corpus $(\sim 5 \times 10 \mathrm{~mm})$ were placed in an organ bath filled with $50 \mathrm{ml}$ of Krebs' solution continuously gassed with $95 \% \mathrm{O}_{2} / 5 \% \mathrm{CO}_{2}$ and maintained at $37^{\circ} \mathrm{C}$. The basal tension was set to $1 \mathrm{gm}$, and the tissue was equilibrated for $90 \mathrm{~min}$. Electrical field stimulation was performed using two platinum wire electrodes about 5 $\mathrm{mm}$ apart, which were connected to a stimulus isolator (A385, WPI). The current was set to $100 \mathrm{~mA}$, and the following pulse parameters were used: pulse width, $0.5 \mathrm{msec}$; frequency, $10 \mathrm{~Hz}$; duration, $10 \mathrm{sec}$. Changes in tension were recorded with an isometric force transducer (FSG-01; Experimetria, Budapest, Hungary) and a MacLab system. The following drugs were used: 2-methyl-5-HT (5- $\mathrm{HT}_{3}$ agonist; donated by Sandoz, Basel, Switzerland), 5-hydroxy-indalpine (5-OHIP; 5-HT $1 \mathrm{P}$ agonist; kindly provided by Kali Chemie, Hannover, Germany), $N$-acetyl-5hydroxytryptophyl-5-hydroxytryptophan amide (5-HTP-DP, 5- $\mathrm{HT}_{1 \mathrm{P}}$ antagonist; kindly provided by Kali Chemie), atropine sulfate, and hexamethonium bromide (the latter obtained from Sigma-Aldrich). They were all dissolved in distilled water, except 5-HTP-DP, which was dis- 


\begin{tabular}{lccc}
\hline $\begin{array}{l}\text { Table 1. 5-HT responses in electrophysiologically classified gastric } \\
\text { myenteric neurons }\end{array}$ & Gastric I & Gastric II & Gastric III \\
\hline $\begin{array}{l}\text { Membrane potential } \\
(\mathrm{mV}, \text { mean } \pm \mathrm{SD})^{a}\end{array}$ & $-47.5 \pm 6.2$ & $-52.1 \pm 7.2$ & $-65.4 \pm 11$ \\
Total population $_{5-\mathrm{HT}_{3} \text {-responsive }}$ & 138 & 151 & 5 \\
$5-\mathrm{HT}_{1 \mathrm{P}^{-} \text {-responsive }}$ & 85 & 92 & 1 \\
$5-\mathrm{HT}_{3}$-and 5-HT & & 17 & 1 \\
responsive $^{-}$ & 15 & 5 & 0 \\
$5-\mathrm{HT}$-insensitive & 6 & 37 & 3 \\
\hline
\end{tabular}

$\overline{{ }^{a} \text { The mean membrane potentials were significantly different between gastric I, II, }}$ and III neurons.

solved in $96 \%$ ethanol and added to the organ bath. Ethanol alone had no effect on the preparation in the concentration used. For evaluation, the maximal response during the electrical stimulation (on response) or the change in basal tone was used. Effects of 2-methyl-5-HT and 5-OHIP on basal tone were investigated in the presence of $200 \mu \mathrm{M}$ hexamethonium or $0.5 \mu \mathrm{M}$ atropine, respectively. Changes of the on responses and the 2-methyl-5-HT-induced tonic contraction were expressed relative to contraction evoked by electrical field stimulation in untreated preparations. Changes in basal tone induced by 5-OHIP were expressed as percentages of the maximal relaxation evoked by electrical field stimulation in the presence of atropine.

\section{RESULTS}

A total of 294 neurons were tested for their responsiveness to 5-HT. Of these neurons 46.9, 51.4, and $1.7 \%$ were gastric I, gastric II, and gastric III cells, respectively (Table 1). Mean resting potentials for the three groups differed significantly from each other (Table 1). The majority of the neurons (222 of 294) tested exhibited responses to spritz application of 5-HT.

\section{Different responses to 5-HT}

In $60.5 \%$ of the neurons (178 of 294) 5-HT application induced a rapid and brief [mean \pm SEM, $3.7 \pm 0.4$ (range, 1.8-7) sec; $n=$ 55] depolarization [12.3 \pm 0.8 (range, 8-30) $\mathrm{mV}$ ] that desensitized rapidly (Figs. 1, 2). During the 5-HT response the input resistance decreased (Fig. 2), and sometimes spontaneous action potentials were observed at the onset of the depolarization (Fig. 1). Previous studies on enteric neurons throughout the gut including guinea pig stomach clearly indicated that such a response to 5-HT was mediated via 5- $\mathrm{HT}_{3}$ receptors (Wade and Wood, 1988; Gershon et al., 1990; Schemann, 1991). 5-HT 3 -mediated responses were observed in all three groups of gastric neurons (Table 1).

In $11.2 \%$ (33 of 294) of the neurons a slowly developing, long-lasting depolarization was observed (Figs. 1, 3). The depolarization [5.7 \pm 3.1 (range, 4-18) $\mathrm{mV} ; n=12]$ usually lasted longer than $1 \mathrm{~min}$ [80.2 \pm 9.6 (range, 42-90 sec)] and was accompanied by an augmented excitability. Injection of hyperpolarizing current pulses indicated an increase in membrane resistance after the application of 5-HT (Fig. 3). In the enteric neurons of the guinea pig stomach and intestine such responses have been characterized as $5-\mathrm{HT}_{1 \mathrm{P}}$ receptor-mediated (Wade and Wood, 1988; Mawe et al., 1989; Schemann, 1991, Mawe and Gershon, 1993; Pan et al., 1997). 5-HT $\mathrm{H}_{\mathrm{P}}$-mediated responses were observed in all three groups of gastric neurons (Table 1).

A small subset of neurons $(3.7 \%, 11$ of 294) showed both $5-\mathrm{HT}_{3}-$ and $5-\mathrm{HT}_{1 \mathrm{P}}$-mediated depolarization. These responses were observed in gastric I and gastric II cells (Table 1).

In $24.6 \%$ of the neurons ( 72 of 294 ) no response to the appli- cation of 5-HT was observed. 5-HT-insensitive neurons were observed in all three groups of gastric neurons (Table 1).

\section{Projection of the neurons}

A total of 257 neurons tested for 5-HT were successfully labeled intracellularly to enable the determination of the axonal projection. Ascending or descending axons were found in 57.6\% (148 of 257 ) or $37.4 \%$ (96 of 257) of the neurons, respectively. Only 5\% (13 of 257) of the neurons were classified as local projecting neurons. Projections of the neurons were not significantly related to the type characterized by electrophysiology.

For further analysis, the neurons were divided into three main groups according to their response to 5-HT: $5-\mathrm{HT}_{3}$-responsive, $5-\mathrm{HT}_{1 \mathrm{p}}$-responsive, and 5-HT-insensitive cells. For these groups the projection of the neurons is shown in Figure 4. The majority $\left(69 \%, 108\right.$ of 157) of the $5-\mathrm{HT}_{3}$-responsive neurons consisted of ascending neurons (Fig. 4). This projection preference was significantly different compared with the 5-HT-insensitive cells $\left(\chi^{2}\right.$ test, $p<0.001$ ). In contrast, $74 \%$ (20 of 27) of the $5-\mathrm{HT}_{1 \mathrm{p}}$ responsive neurons were classified as descending neurons (Fig. 4). The projection of the $5-\mathrm{HT}_{1 \mathrm{p}}$-responsive cells was significantly different from 5- $\mathrm{HT}_{3}$-responsive neurons. In the 5-HT-insensitive group, $42 \%$ (29 of 69 ) were ascending and 58\% (40 of 69) were descending neurons, respectively.

In some neurons $(n=140)$ it was possible to trace the axons to their terminal regions. Varicose endings were observed exclusively in the muscle layers (58\%, putative motor neurons), only within the myenteric plexus ( $31 \%$, nonmotor neurons), or in both regions (11\%, putative multitargeted neurons), as has been described previously (Schemann and Schaaf, 1995). 5-HTresponsive and -insensitive cells belonged to all three classes, and no relation was found between 5-HT-mediated response and the putative function as a motor, nonmotor, or multitargeted neuron.

These data indicate a differential projection preference of 5 - $\mathrm{HT}_{3}$-responsive neurons and $5-\mathrm{HT}_{1 \mathrm{p}}$-responsive neurons in ascending and descending directions, respectively.

\section{Neurochemical coding}

In 187 neurons the chemical coding could be determined. Cholinergic and nitrergic neurons made up 68 and 32\%, respectively. Of this sample most $(84 \%, 96$ of 115$)$ of the ascending neurons were cholinergic, whereas most $(63 \%, 40$ of 64$)$ of the descending neurons expressed NADPH-diaphorase activity. Only one neuron exhibited ChAT immunoreactivity and was NADPHdiaphorase-reactive and showed a $5-\mathrm{HT}_{3}$ and $5-\mathrm{HT}_{1 \mathrm{p}}$ response.

There was a significant difference in the projection and the neurochemical coding between the populations of $5-\mathrm{HT}_{3}-$ and $5-\mathrm{HT}_{1 \mathrm{P}}$-responsive neurons. Neurons that showed $5-\mathrm{HT}_{3}-$ mediated responses were predominantly cholinergic $(79 \%)$ and had ascending projections (Fig. 5). Considering only the cholinergic $5-\mathrm{HT}_{3}$-responsive neurons, $81 \%$ of them had ascending projections. Only $21 \%$ of the $5-\mathrm{HT}_{3}$-responsive cells were NADPH-diaphorase-positive. The majority of the nitrergic neurons that showed $5-\mathrm{HT}_{3}$ responses had ascending projections (15 of 24). This projection pattern was significantly different from that of $5-\mathrm{HT}_{1 \mathrm{p}}$-responsive and 5-HT-insensitive nitrergic neurons, which had primarily descending projections (Fig. 5).

In contrast to the $5-\mathrm{HT}_{3}$-responsive cells, the majority of the

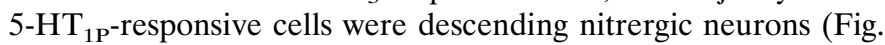
5). Almost all of the nitrergic $5-\mathrm{HT}_{1 \mathrm{P}}$-responsive cells had descending projections $(93 \%)$. No preferential projection was observed for the cholinergic 5-HT $\mathrm{H}_{1 \mathrm{p}}$-responsive neurons (Fig. 5). 

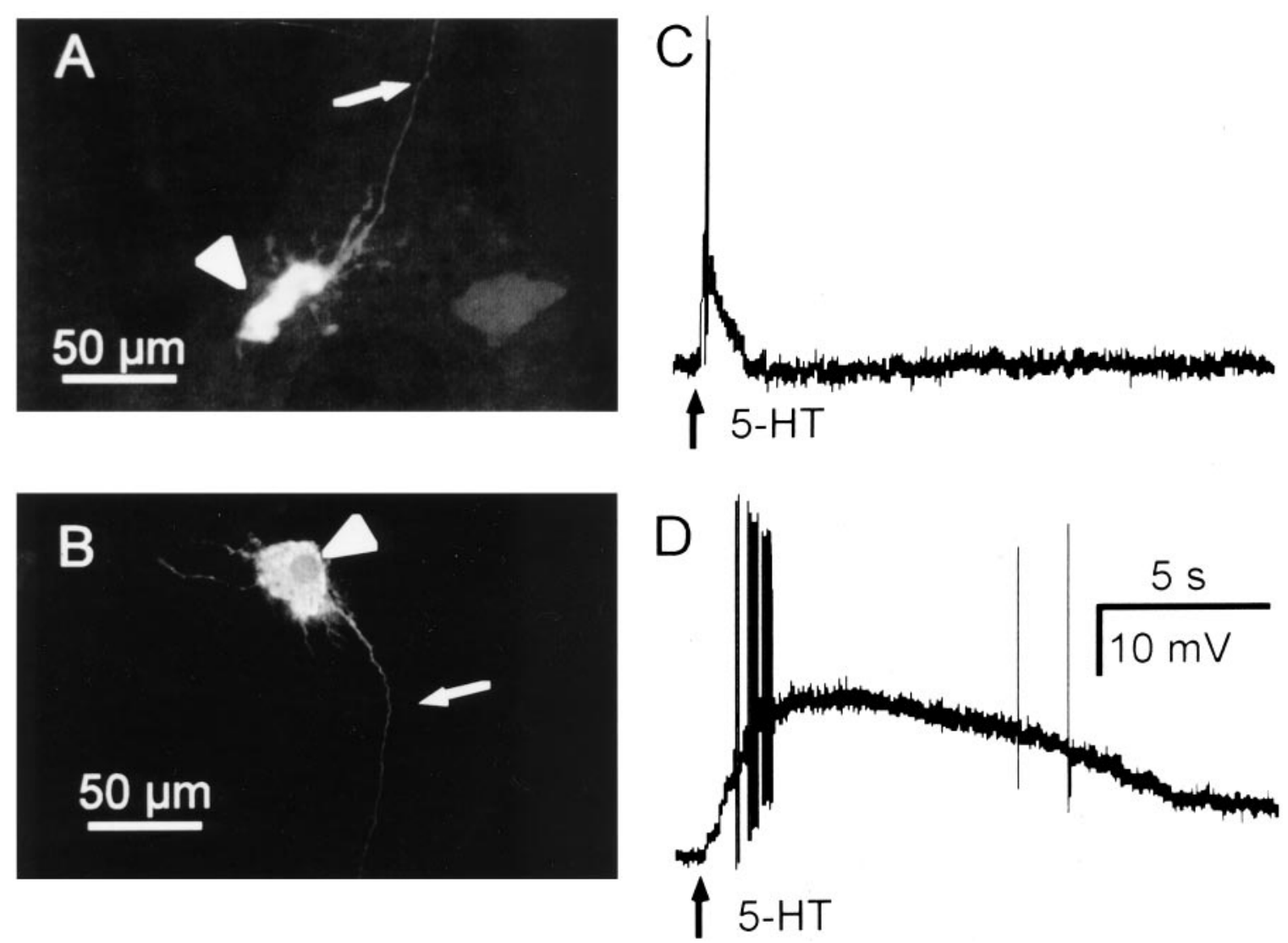

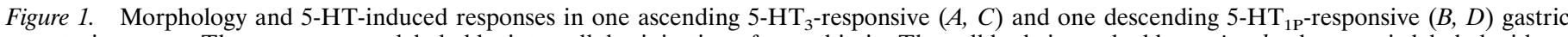
myenteric neuron. The neurons were labeled by intracellular injection of neurobiotin. The cell body is marked by a triangle; the axon is labeled with an arrow. Scale bar, $50 \mu \mathrm{m}$. Note that 5-HT evoked a typical 5- $\mathrm{HT}_{3}$ receptor-mediated rapid depolarization, accompanied by some action potentials at the onset of the depolarization in the ascending neuron $(C)$, whereas a long-lasting depolarization accompanied by action potentials was observed in the descending neuron, typical for $5-\mathrm{HT}_{1 \mathrm{P}}$ receptor-mediated responses $(D)$.

Neurons that expressed both $5-\mathrm{HT}_{3}$ and $5-\mathrm{HT}_{1 \mathrm{p}}$ responses were cholinergic (four of seven) or nitrergic (two of seven) or contained both neurotransmitters (one of seven). They exhibited no preferential projection. In the 5-HT-insensitive group, both cholinergic and nitrergic neurons were found. Both groups exhibited no different preferential projection compared with all neurons of the respective neurochemical code (Fig. 5).

Because there was a correlation between neurochemical coding and projection, the question arises whether the occurrence of a $5-\mathrm{HT}_{3}$ - and $5-\mathrm{HT}_{1 \mathrm{p}}$-mediated response was related rather to the projection than to the neurochemical coding of the cells. This could be tested for the population of $5-\mathrm{HT}_{3}$-responsive neurons. These neurons projected independent of their cholinergic or nitrergic phenotype primarily in an ascending projection. There was no significant difference in the projection preference of the cholinergic and nitrergic 5- $\mathrm{HT}_{3}$-responsive neurons (Fig. 5). This might indicate that the type of 5-HT response may be more related to the projection than to the chemical code of the neurons. However, the population of ascending nitrergic neurons was much smaller compared with the population of ascending cholinergic neurons. Functionally, 5- $\mathrm{HT}_{3}$ receptors located on ascending cholinergic neurons might be therefore more relevant.

SP immunoreactivity could only observed in colchicine-treated preparations. Of 136 neurobiotin-labeled neurons 20 (15\%) were SP-positive. These cells were also ChAT-positive and did not express NADPH-diaphorase reactivity. The vast majority $(90 \%$,
17 of 19) of the SP-positive cells exhibited an ascending projection $(p<0.05)$. Fifteen SP-positive neurons $(75 \%)$ showed a $5-\mathrm{HT}_{3}$ response, and all of them had an ascending projection. Only two cells had a 5-HT $1 \mathrm{P}$-response, and three cells were 5-HT insensitive.

These data indicated that most $5-\mathrm{HT}_{3}$-responsive neurons were ascending cholinergic cells, which in part also contained SP, whereas most $5-\mathrm{HT}_{1 \mathrm{p}}$-responsive cells were descending nitrergic neurons.

\section{Effect of $5-\mathrm{HT}_{3}$ and $5-\mathrm{HT}_{1 \mathrm{P}}$ agonists on gastric motility}

To evaluate possible functional implications of our findings, the responses of stomach circular muscle strips to application of the 5-HT agonists were examined. Electrical stimulation resulted in a biphasic or triphasic response, which consisted of an initial contraction during the stimulus (on response), a second contraction after the end of the stimulus (off contraction), and a longer-lasting relaxation (Fig. 6A,B). Application of the 5- $\mathrm{HT}_{3}$ agonist 2methyl-5-HT caused a dose-dependent increase in the on response (Fig. 6A,C). In contrast, bath application of the $5-\mathrm{HT}_{1 \mathrm{P}}$ agonist 5-OHIP resulted in a dose-dependent decrease in the on response (Fig. 6B,C).

Application of 2-methyl 5-HT also evoked a dose-dependent tonic contraction (Fig. 6D). The contraction induced by $5 \mu \mathrm{M}$ 2 -methyl-5-HT was significantly reduced by $77 \%$ in $0.5 \mu \mathrm{M}$ atropine $(n=2)$, strongly indicating the involvement of cholinergic 

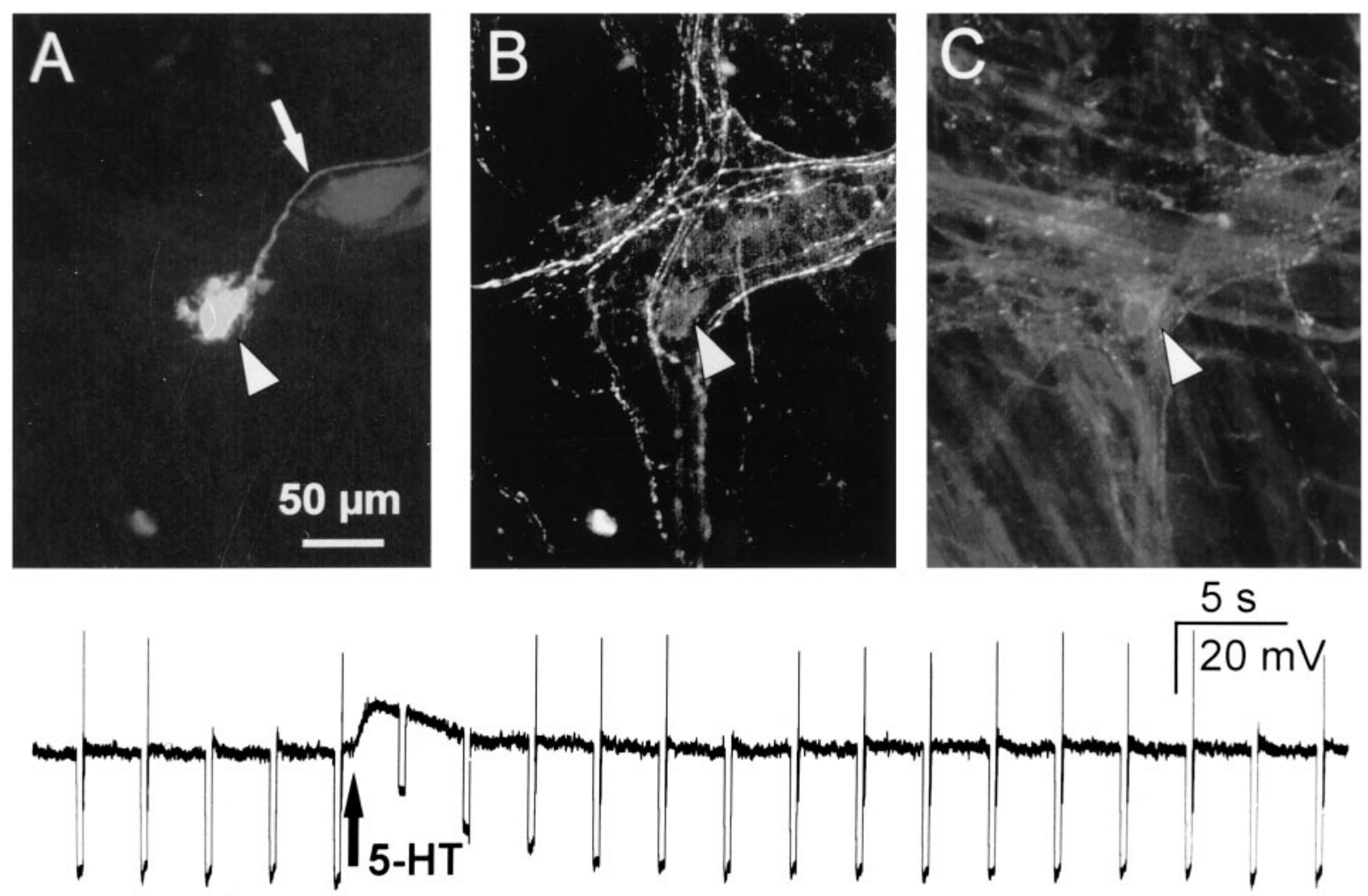

Figure 2. Immunohistochemical staining of a 5- $\mathrm{HT}_{3}$-responsive ChAT- and SP-positive neuron. $A$, Neurobiotin staining of the cell. The cell body is marked by a triangle, the ascending axon with an arrow. The same cell shows immunoreactivity for SP $(B)$ and ChAT $(C)$. The scale bar in $A$ also applies to $B$ and $C$. Bottom, Change in membrane potential after the application of 5-HT (arrow) of the same cell as in $A$. Hyperpolarizing current pulses were injected to show changes in membrane resistance.

motor neurons. In contrast, 5-OHIP evoked a dose-dependent relaxation of the gastric smooth muscle (Fig. $6 E$ ). The relaxation evoked by $10 \mu \mathrm{M}$ 5-OHIP was blocked when the tissue was pretreated in a $50 \mu \mathrm{M}$ concentration of the $5-\mathrm{HT}_{1 \mathrm{P}}$ antagonist 5-HTP-DP $(n=2)$.

\section{DISCUSSION}

\section{Characterization of 5-HT-responsive myenteric neurons}

Neural reflex circuits controlling gut functions reside within the enteric nervous system (Langley, 1921). The circuitry for the peristaltic reflex, which mediates contraction above and relaxation below a distension stimulus, is based on polarized projection patterns of excitatory cholinergic and inhibitory nitrergic neurons (for review, see Costa et al., 1996). In this study we demonstrated for the first time that specific components of enteric reflex pathways were differentially activated by 5 -HT receptor subtypes. $5-\mathrm{HT}_{3}$-mediated responses were predominantly observed in cholinergic ascending neurons, whereas $5-\mathrm{HT}_{1 \mathrm{P}^{-}}$ mediated responses occurred in nitrergic descending neurons. The neurochemical coding and projection of our sample confirmed previous data in that the relative number of labeled cholinergic and nitrergic neurons recorded in this study closely matched that observed in the entire population of gastric myenteric neurons (Schemann and Schaaf, 1995; Schemann et al., 1995), indicating no sampling bias. In addition to advancing basic knowledge on modulation of enteric reflexes, our data might contribute to the understanding of the mode of action of those prokinetic substances that exert their effect through serotonergic mechanisms.

Immunohistochemical and electrophysiological characterization of subclasses of enteric neurons has led to the proposal that both cholinergic and nitrergic neurons might function as interneurons or motor neurons (Costa and Brookes, 1994; Schemann et al., 1995; Costa et al., 1996). In the present study, the two functionally distinct classes responded equally to 5-HT. Therefore, 5-HT could affect gastric functions such as motility or secretion directly by activating the motor neurons and/or indirectly via activation of interneurons. The location of 5-HTpositive fibers and nerve endings solely within the gastric myenteric plexus is in accordance with a neurotransmitter role for 5-HT in interneurons in the stomach (Schemann et al., 1995). In the small intestine and the colon, 5-HT has been identified as one of the transmitters in a subpopulation of descending interneurons (Erde et al., 1985; Costa and Brookes, 1994; Wardell et al., 1994).

\section{Functional aspect of 5-HT-mediated responses: role of 5-HT in polarized reflex circuits}

Based on our study, stimulation of $5-\mathrm{HT}_{3}$ receptors would predominantly result in a release of acetylcholine and substance $\mathrm{P}$, whereas $5-\mathrm{HT}_{1 \mathrm{P}}$ responses should evoke a release of nitric oxide. Because the majority of the nitrergic neurons in the stomach also contain vasoactive intestinal peptide and neuropeptide Y (Schemann et al., 1995), release of these peptides might also be enhanced. There is good evidence that 5-HT can produce motor effects via enteric neurons (Gershon et al., 1990; Read and Gwee, 

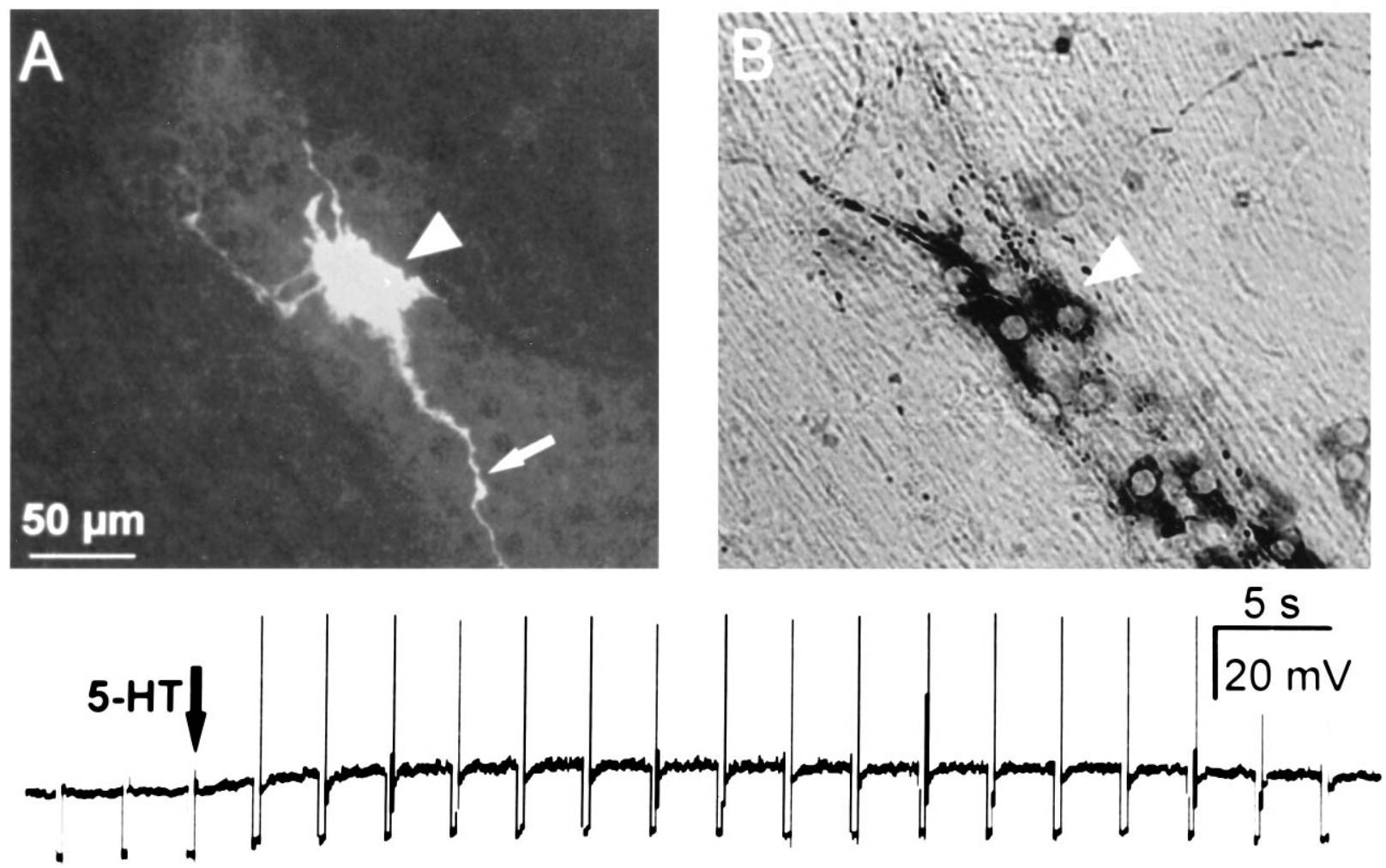

Figure 3. Immunohistochemical staining of a $5-\mathrm{HT}_{1 \mathrm{p}}$-responsive nitrergic neuron. $A$, Neurobiotin staining of the cell. The cell body is marked by a triangle, the descending axon by an arrow. $B$, The same cell shows NADPH-diaphorase reactivity. The scale bar in $A$ also applies to $B$. Bottom, The cell in $A$ shows a slow depolarization and enhanced excitability (indicated by anodal break excitation) after the application of 5-HT (arrow).

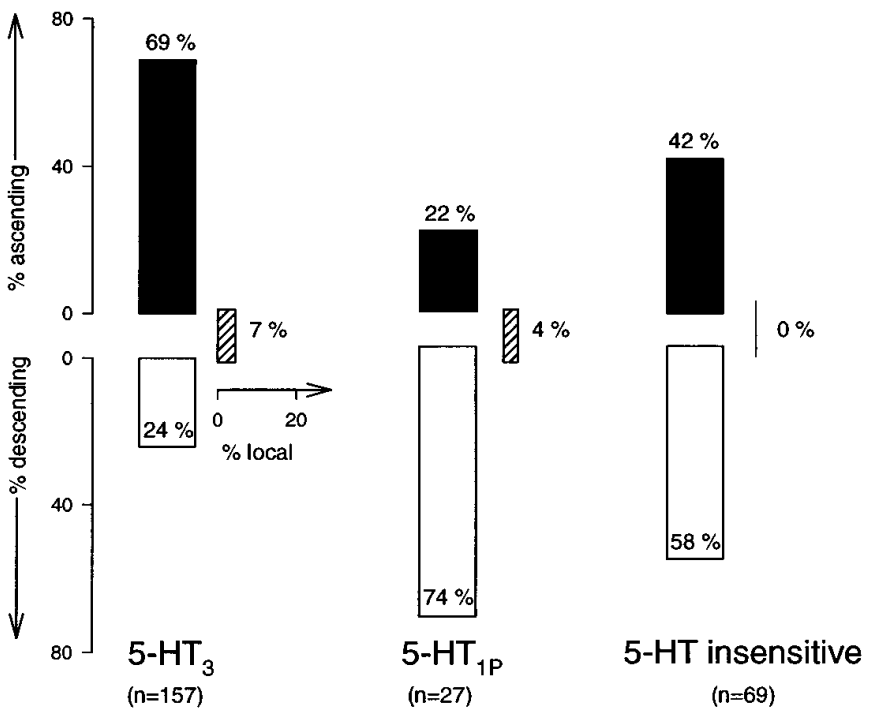

Figure 4. Projection of gastric myenteric neurons with different responses to 5-HT. Ascending and descending projections are indicated by ascending and descending bars, respectively. Local projections are shown as horizontal bars. For each response to 5-HT a graph shows the percentage of cells having a certain projection with respect to the total number of cells exhibiting this 5-HT response. Projection patterns for 5- $\mathrm{HT}_{3}$ cells differ significantly from those of $5-\mathrm{HT}_{1 \mathrm{P}}$ cells and 5-HT-insensitive cells.

1994) and can stimulate cholinergic neurons in the guinea pig stomach (Bülbring and Gershon, 1967). Our study confirmed previous results that the $5-\mathrm{HT}_{3}$ agonist 2-methyl-5-HT increased both basal and stimulus-evoked gastric tone (Buchheit and Buhl,
1994). Both effects could be blocked by the $5-\mathrm{HT}_{3}$ antagonist tropisetron (Buchheit and Buhl, 1994). We further demonstrated that the $5-\mathrm{HT}_{3}$-evoked contractile response was cholinergic. Additional involvement of excitatory neuropeptides is strongly suggested by our finding that almost all SP-immunoreactive cells had 5- $\mathrm{HT}_{3}$ responses. $5-\mathrm{HT}_{3}$-mediated release of both acetylcholine and tachykinins has been shown in the guinea pig colon. Here contractile responses to 2-methyl-5-HT were completely blocked in the presence of the cholinergic antagonist hyoscine and the tachykinin antagonist spantide (Woolard et al., 1994). 5-HT has been detected in gastric myenteric neurons (Schemann et al., 1995), and its neuronal release has been demonstrated (Bülbring and Gershon, 1967). However, no clear-cut involvement of 5-HT released from intrinsic or vagal neurons in motor control could be demonstrated (Buchheit and Buhl, 1994; Desai et al., 1994). The major source of 5-HT in the gut is the enterochromaffin cells. In the intestine, it has been suggested that these cells mediate motor and secretory responses in the gut by releasing 5-HT in response to mechanical stimuli; the 5-HT then stimulates intrinsic nerves (Kirchgessner et al., 1992, 1996; Wade et al., 1996).

In contrast to the action of the $5-\mathrm{HT}_{3}$ agonist, the $5-\mathrm{HT}_{1 \mathrm{P}}$ agonist 5-OHIP decreased the amplitude of the contraction evoked by electrical field stimulation and induced a 5-HTP-DPsensitive relaxation, supporting the idea that 5-HT activated inhibitory pathways (Bogers et al., 1991; Meulemans et al., 1993; Briejer et al., 1995). Additional effects at the muscular level cannot be ruled out, because $5-\mathrm{HT}_{1 \mathrm{P}}$ effects were also observed directly on muscle cells in the small intestine (Kuemmerle et al., 1993). Therefore, most relevant in this context are our studies on electrically induced stimulations, which demonstrate the significance of neuronal $5-\mathrm{HT}_{1 \mathrm{P}}$ receptors for the control of gastric 

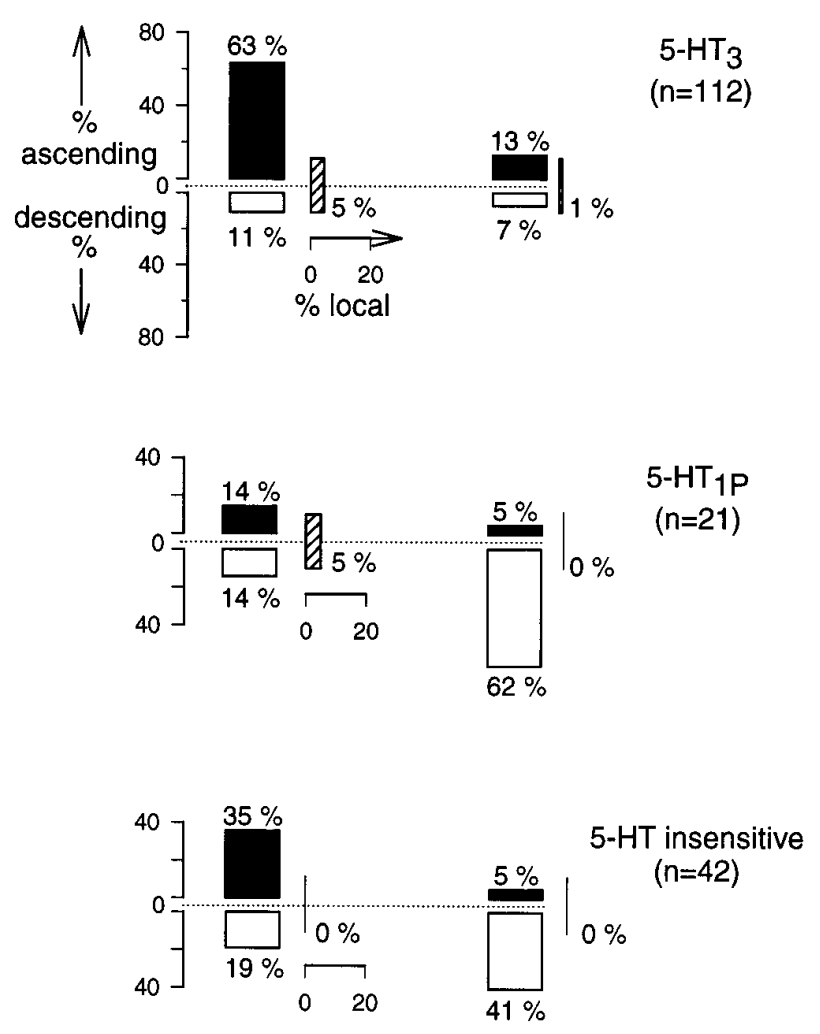

ChAT NADPH

Figure 5. Comparison of myenteric gastric neurons with different neurochemical coding with respect to their projection and response to 5-HT. Ascending and descending projections are indicated by ascending and descending bars, respectively. Local projections are shown as horizontal bars. The percentages are related to the respective total number of cells exhibiting a certain response to 5-HT. For significances in the differences between the groups, see Results.

motility. Based on our results, one mechanism by which 5-HT could reduce the amplitude of the evoked contractions would be the inhibition of acetylcholine release via the activation of 5-HTresponsive nitrergic neurons. This notion is supported by a recent study showing that removal of the inhibitory tone by nitric oxide synthase inhibitors could increase cholinergic contractions at the prejunctional level (Baccari et al., 1993). In agreement, nitric oxide evoked a presynaptic reduction of excitatory input to myenteric neurons, although this has been attributed mainly to inhibition of peptidergic synapses (Tamura et al., 1993). In the stomach, it has been shown that neuropeptide $\mathrm{Y}$ acted presynaptically to reduce cholinergic fast EPSPs, which would result in reduced release of acetylcholine (Schemann and Tamura, 1991). Because most nitrergic neurons in the stomach were neuropeptide Y-immunoreactive (Schemann et al., 1995), this peptide might also be involved in the 5-OHIP-induced decrease of the stimulusevoked contractions.

Compared with the rather powerful excitatory effect of the 5- $\mathrm{HT}_{3}$ agonist 2-methyl-5-HT on muscle contractions, the inhibitory effect of the 5-HT $1 \mathrm{P}$ agonist 5-OHIP was, although significant, less pronounced. This might be explained by the sizes of the cell populations activated by $5-\mathrm{HT}_{3}$ or $5-\mathrm{HT}_{1 \mathrm{P}}$ receptors. $\mathrm{Al}-$ though $67 \%$ of the total population of gastric myenteric neurons were cholinergic, only 29\% were nitrergic (Schemann et al., 1995).
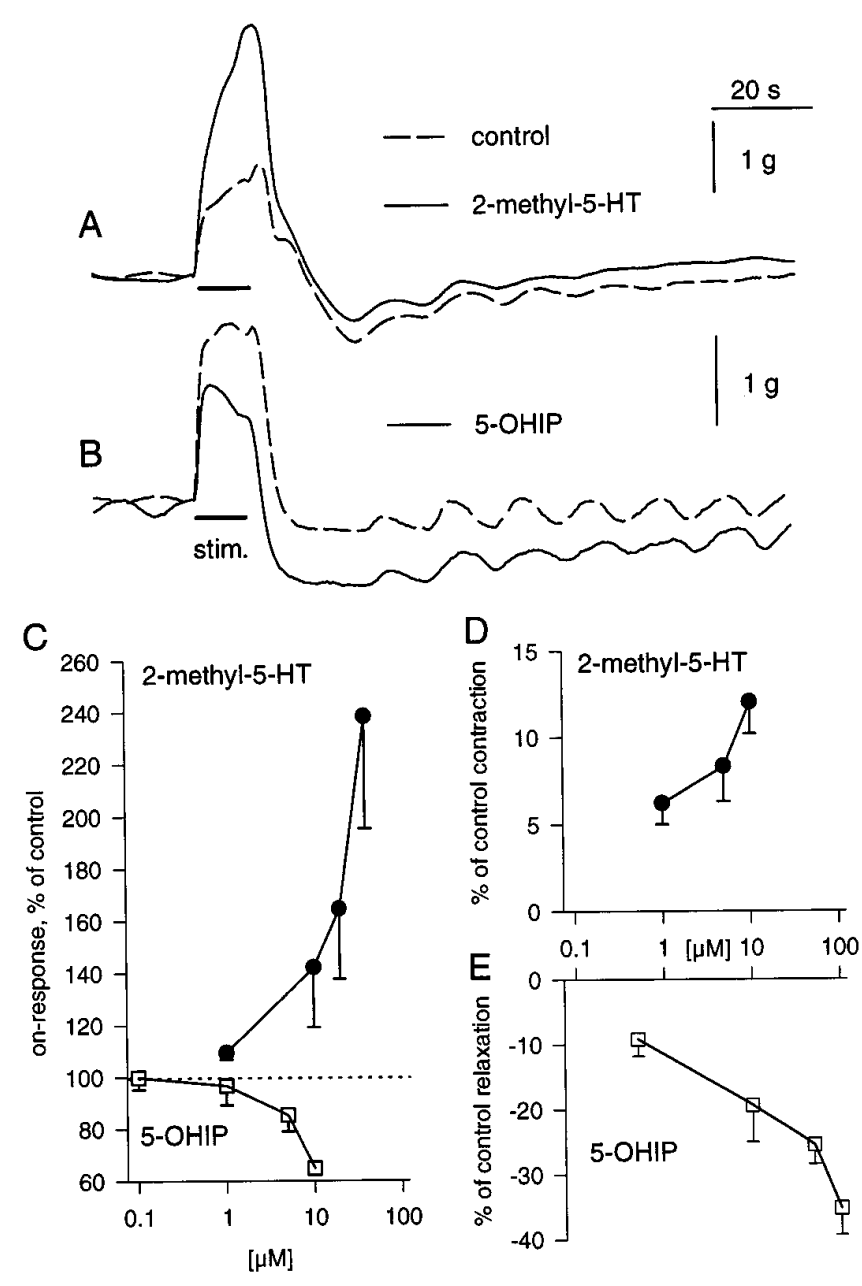

Figure 6. Effects and dose-response curves for the application of 2methyl-5-HT (5- $\mathrm{HT}_{3}$ agonist) and 5-OHIP (5-HT $\mathrm{Hp}_{1 \mathrm{p}}$ agonist) in organ bath experiments. Traces in $A$ show an increase of the on response to electrical field stimulation with a concentration of $20 \mu \mathrm{M}$ 2-methyl-5-HT in the organ bath. The on response in $B$ is decreased with $10 \mu \mathrm{M} 5$-OHIP in the organ bath. In $C$ the dose-response curves for the effects of both agonists on the on response are shown (mean \pm SEM of preparations from 4-7 animals). The amplitude of the on response was set at $100 \%$ (broken line). Effects of the two 5-HT agonists on basal tone are shown in $D$ and $E$ as dose-response curves. These experiments were made in the presence of $200 \mu \mathrm{M}$ hexamethonium $(D)$ or $0.5 \mu \mathrm{M}$ atropine $(E)$. The data are given as percentages of the response to electrical field stimulation (mean $\pm \mathrm{SEM}$ of preparations from 2-3 animals).

In addition, the present study revealed that the proportion of nitrergic neurons activated by $5-\mathrm{HT}_{1 \mathrm{P}}$ receptors is much less than the proportion of cholinergic neurons activated by $5-\mathrm{HT}_{3}$ receptors.

The differential location of $5-\mathrm{HT}_{3}$ and $5-\mathrm{HT}_{1 \mathrm{P}}$ receptors on myenteric ascending cholinergic and descending nitrergic neurons and the opposite action of the respective specific agonist on the contractile activity of muscle strips suggested that 5-HT could activate a polarized reflex circuit that resulted in coordinated motor activity. Such polarized circuits, which consisted of ascending cholinergic and descending nitrergic neurons, have been described in the intestine and the stomach (Costa and Brookes, 1994; Wood, 1994; Schemann and Schaaf, 1995). Although in the intestine there is good evidence that these circuits are involved in the peristaltic reflex (Costa and Brookes, 1994), a similar peristaltic reflex has not been unequivocally demonstrated in the 
stomach. In the intestine, 5-HT released from enterochromaffin cells has been postulated to be involved in the stimulation of the putative intrinsic sensory neurons, which finally evoke a peristaltic reflex (Gershon et al., 1990; Kirchgessner et al., 1992, 1996). Such a mechanism might also be operative in the stomach. Indeed, mechanical and chemical stimuli, vagal stimulation, or stress can increase gastric 5-HT levels (Gershon et al., 1990; Racke et al., 1990; Ciurzynska et al., 1994) and might consequently stimulate the gastric polarized circuits. In preparations of the small intestine in which the mucosa was removed, mechanical stimuli still evoked 5- $\mathrm{HT}_{3}$-mediated ascending contractions (Yuan et al., 1994) and descending relaxation (Messori et al., 1995), indicating that neural pathways alone can initiate 5-HT induced peristalsis.

In addition to a possible general activation of both excitatory and inhibitory neurons, there is evidence of a preferential activation of enteric neurons, which might favor inhibition or excitation of gastric motility. Low- and high-affinity 5-HT binding sites have been described, with $5-\mathrm{HT}_{1 \mathrm{P}}$ receptors expressing the highaffinity binding (Gershon et al., 1990). Consequently, different amounts of 5-HT released on physiological stimuli or under pathological conditions might result in a dose-dependent and preferential binding to a specific receptor subtype.

Studies on gastric emptying of a liquid meal demonstrated decreased emptying by specific $5-\mathrm{HT}_{1 \mathrm{P}}$ agonists (Mawe et al., 1989; Gershon et al., 1990). Because 5-HT ${ }_{1 \mathrm{P}}$ antagonist increased gastric emptying, a tonic 5- $\mathrm{HT}_{1 \mathrm{P}}$-mediated activation of inhibitory neurons has been postulated (Mawe et al., 1989; Gershon et al., 1990). Our study provides the first indication that such an effect could be based on a specific $5-\mathrm{HT}_{1 \mathrm{P}}$ sensitivity of descending inhibitory neurons.

The actions of $5-\mathrm{HT}_{3}$ receptor antagonists on gastric emptying are controversial. Acceleration (Buchheit et al., 1985; Akkermans et al., 1988), delay (Stacher et al., 1990), and no effect have been reported (Mawe et al., 1989; Gershon et al., 1990). In part, the different results could be explained by the nutrient content of the meal, indicating that $5-\mathrm{HT}_{3}$ receptors located on primary afferent nerve fibers and centrally controlled reflexes are involved (Read and Gwee, 1994). Additionally, it has to be considered that many of the 5- $\mathrm{HT}_{3}$ antagonists used in gastric emptying studies crossreacted with other serotonin receptors (Gershon et al., 1990).

In conclusion, this study provides evidence of a differential location of $5-\mathrm{HT}_{1 \mathrm{P}}$ and $5-\mathrm{HT}_{3}$ receptors on a subpopulation of descending nitrergic and ascending cholinergic myenteric neurons, respectively. Local activation of neuronal subpopulations, as can be achieved by release of 5-HT from interneurons or of non-neuronal sources, might affect peristaltic contractions and modulate gastric emptying.

\section{REFERENCES}

Akkermans LM, Vos A, Hoekstra A, Roelofs JM, Horowitz M (1988) Effect of ICS 205-930 (a specific 5-HT3 receptor antagonist) on gastric emptying of a solid meal in normal subjects. Gut 29:1249-1252.

Baccari MC, Bertini M, Calamai F (1993) Effects of L-NG-nitro arginine on cholinergic transmission in the gastric muscle of the rabbit. NeuroReport 4:1102-1104.

Bayliss WM, Starling EH (1899) The movements and innervation of the small intestine. J Physiol (Lond) 24:99-143.

Bogers JJ, Pelckmans PA, Boeckxstaens GE, De Man JG, Herman AG, Van Maercke YM (1991) The role of nitric oxide in serotonin-induced relaxations in the canine terminal ileum and ileocolonic junction. Naunyn Schmiedebergs Arch Pharmacol 344:716-719.

Briejer MR, Akkermans LM, Meulemans AL, Lefebvre RA, Schuurkes JA (1995) 5-HT-induced neurogenic relaxations of the guinea-pig proximal colon: investigation into the role of ATP and VIP in addition to nitric oxide. Naunyn Schmiedebergs Arch Pharmacol 351:126-135.

Buchheit KH, Buhl T (1994) Stimulant effects of 5-hydroxytryptamine on guinea pig stomach preparations in vitro. Eur J Pharmacol 262:91-97.

Buchheit KH, Costall B, Engel G, Gunning SJ, Naylor RJ, Richardson BP (1985) 5-Hydroxytryptamine receptor antagonism by metoclopramide and ICS 205-930 in the guinea-pig leads to enhancement of contractions of stomach muscle strips induced by electrical field stimulation and facilitation of gastric emptying in-vivo. J Pharm Pharmacol 37:664-667.

Bülbring E, Gershon MD (1967) 5-Hydroxytryptamine participation in the vagal inhibitory innervation of the stomach. J Physiol (Lond) 192:823-846.

Ciurzynska G, Dzierzkowska J, Maslinski S (1994) Gastric cytoprotective activity of endogenous 5-HT. J Physiol Pharmacol 45:517-532.

Costa M, Brookes SJH (1994) The enteric nervous system. Am J Gastroenterol 89:S129-S137.

Costa M, Brookes SJH, Steele PA, Gibbins I, Burcher E, Kandiah CJ (1996) Neurochemical classification of myenteric neurones in the guinea-pig ileum. Neuroscience 75:949-967.

Desai KM, Warner TD, Vane JR (1994) 5-HT3 receptors do not mediate vagally-induced relaxation or contraction of the isolated stomach of the guinea-pig. Br J Pharmacol 111:346-350.

Erde SM, Sherman DL, Gershon MD (1985) Morphology and serotonergic innervation of physiologically identified cells of the guinea pig's myenteric plexus. J Neurosci 5:617-633.

Fox A, Morton IK (1990) An examination of the 5-HT3 receptor mediating contraction and evoked-acetylcholine release in the guinea-pig ileum. Br J Pharmacol 101:553-558.

Furness JB, Young HM, Pompolo S, Bornstein JC, Kunze WA, McConalogue K (1995) Plurichemical transmission and chemical coding of neurons in the digestive tract. Gastroenterology 108:554-563.

Gershon MD (1967) Effects of tetrodotoxin on innervated smooth muscle preparations. Br J Pharmacol 29:259-279.

Gershon MD, Wade PR, Kirchgessner AL, Tamir H (1990) 5-HT receptor subtypes outside the central nervous system. Roles in the physiology of the gut. Neuropsychopharmacology 3:385-395.

Kirchgessner AL, Tamir H, Gershon MD (1992) Identification and stimulation by serotonin of intrinsic sensory neurons of the submucosal plexus of the guinea pig gut: activity-induced expression of Fos immunoreactivity. J Neurosci 12:235-248.

Kirchgessner AL, Liu MT, Gershon MD (1996) In situ identification and visualization of neurons that mediate enteric and enteropancreatic reflexes. J Comp Neurol 371:270-286.

Kuemmerle JF, Martin DC, Murthy KS, Kellum JM, Grider JR, Makhlouf, GM (1993) Coexistence of contractile and relaxant 5-hydroxytryptamine receptors coupled to distinct signaling pathways in intestinal muscle cells: convergence on the pathways on $\mathrm{Ca}^{2+}$ mobilization. Mol Pharmacol 42:1090-1096.

Langley, JN (1921) The autonomic nervous system, part I. Cambridge: Heffer and Sons.

Mawe GM, Gershon MD (1993) The 5-HT 1 P receptor. Drug News Perspect 6:24-30.

Mawe GM, Branchek TA, Gershon MD (1989) Blockade of 5-HTmediated enteric slow EPSPs by BRL 24924: gastrokinetic effects. Am J Physiol 257:G386-G396.

Messori E, Candura SM, Coccini T, Balestra B, Tonini M (1995) 5- $\mathrm{HT}_{3}$ receptor involvement in descending reflex relaxation in the rabbit isolated distal colon. Eur J Pharmacol 286:205-208.

Meulemans AL, Helsen LF, Schuurkes JA (1993) The role of nitric oxide (NO) in 5-HT-induced relaxations of the guinea-pig stomach. Naunyn Schmiedebergs Arch Pharmacol 348:424-430.

Pan H, Wang HY, Friedman E, Gershon MD (1997) Mediation by protein kinases $\mathrm{C}$ and $\mathrm{A}$ of $\mathrm{G}_{\mathrm{o}}$-linked slow responses of enteric neurons to 5-HT. J Neurosci 17:1011-1024.

Racke K, Schworer H, Kilbinger H (1990) Effects of the benzodiazepine receptor agonist midazolam and antagonist flumazenil on 5hydroxytryptamine release from guinea-pig intestine in vitro. Indirect support for a "natural" benzodiazepine-like substance in the intestine. Naunyn Schmiedebergs Arch Pharmacol 341:1-7.

Read NW, Gwee KA (1994) The importance of 5-hydroxytryptamine receptors in the gut. Pharmacol Ther 62:159-173.

Schemann M (1991) 5-Hydroxytryptamine-mediated responses in myenteric neurons of the guinea-pig gastric corpus: effect of ICS 205-930 and cisapride. J Gastrointest Motil 3:255-262. 
Schemann M, Schaaf C (1995) Differential projection of cholinergic and nitroxidergic neurons in the myenteric plexus of guinea pig stomach. Am J Physiol 269:G186-G195.

Schemann M, Tamura K (1991) Presynaptic inhibitory effects of the peptides NPY, PYY and PP on nicotinic EPSPs in guinea-pig gastric myenteric neurones. J Physiol (Lond) 451:79-89.

Schemann M, Wood JD (1989) Electrical behaviour of myenteric neurones in the gastric corpus of the guinea-pig. J Physiol (Lond) 417:501-518.

Schemann M, Schaaf C, Mäder M (1995) Neurochemical coding of enteric neurons in the guinea-pig stomach. J Comp Neurol 353:161-178.

Stacher G, Bergmann H, Schneider C, Steiner Mittelbach G, Gaupmann G, Steinringer H, Abatzi TA, Stacher Janotta G (1990) Effects of the 5-HT3 receptor antagonist ICS 205-930 on fat-delayed gastric emptying and antral motor activity. Br J Clin Pharmacol 30:41-48.

Tamura K, Schemann M, Wood JD (1993) Actions of nitric oxidegenerating sodium nitroprusside in myenteric plexus of guinea-pig small intestine. Am J Physiol 265:G887-G893.

Wade PR, Wood JD (1988) Actions of serotonin and substance P on myenteric neurons of guinea-pig distal colon. Eur J Pharmacol 148:1-8.
Wade PR, Chen J, Jaffe B, Kassem IS, Blakely RD, Gershon MD (1996) Localization and function of a 5-HT transporter in crypt epithelia of the gastrointestinal tract. J Neurosci 16:2352-2364.

Wang L, Savedia S, Benjamin M, Perdue MH (1995) The role of mast cells in intestinal immunophysiology. Adv Exp Med Biol 371A:287-292.

Wardell CF, Bornstein JC, Furness JB (1994) Projections of 5hydroxytryptamine-immunoreactive neurons in guinea-pig distal colon. Cell Tissue Res 278:379-387.

Wood JD (1994) Physiology of the enteric nervous system. In: Physiology of the gastrointestinal tract (Johnson LR, ed), pp 423-482. New York: Raven.

Woolard DJ, Bornstein JC, Furness JB (1994) Characterization of 5-HT receptors mediating contraction and relaxation of the longitudinal muscle of guinea-pig distal colon in vitro. Naunyn Schmiedebergs Arch Pharmacol 349:455-462.

Yuan SY, Bornstein JC, Furness JB (1994) Investigation of the role of 5-HT3 and 5-HT4 receptors in ascending and descending reflexes to the circular muscle of guinea-pig small intestine. $\mathrm{Br} \mathrm{J}$ Pharmacol 112:1095-1100. 